\title{
SEROPREVALENCE OF INFECTIOUS BOVINE RHINOTRACHEITIS (IBR) IN NORTH EASTERN (NE) STATES OF INDIA
}

\author{
Sharanagouda S. Patil ${ }^{1}$, R. Ravindran ${ }^{2}$, R. Sowjanyakumari ${ }^{1}$, K.P. Suresh ${ }^{1}$, Jagadish Hiremath ${ }^{1}$, \\ Divakar Hemadri ${ }^{1}$, Chandan Shivamallu ${ }^{3}$, Habibar Rahman ${ }^{4}$
}

${ }^{1}$ ICAR-National Institute of Veterinary Epidemiology and Disease Informatics (NIVEDI), Yelahanka, Bengaluru-560064, Karnataka, India ${ }^{2}$ College of Veterinary Science, GADAVASU, Ludhiana, Punjab, India

${ }^{3}$ Department of Biotechnology and Bioinformatics, School of Life Sciences, JSS Academy of Higher Education and Research, Mysore, Karnataka, India

${ }^{4}$ Regional Representative for South Asia, ILRI, NASC Complex, Pusa, New Delhi, India

Received - February 20, 2021; Revision - April 27, 2021; Accepted - May 26, 2021

Available Online - June 25, 2021

DOI: http://dx.doi.org/10.18006/2021.9(3).305.310

KEYWORDS
Infectious bovine rhinotracheitis
IBR
Assam
Manipur
Meghalaya
Mizoram
Seroprevalence
Sikkim

\begin{abstract}
Infectious bovine rhinotracheitis (IBR) is an infectious disease caused by BoHV-1 and belongs to the Herpesviridae family. IBR is endemic in India including north eastern states of the country. Hence the study was undertaken to understand the seroprevalence of IBR in north eastern parts of the country. A total of 3125 cattle (Holstein Friesian crossbred) serum samples from 35 districts of five north eastern states (Assam, Manipur, Meghalaya, Mizoram, and Sikkim) of India were screened for infectious bovine rhinotracheitis (IBR) virus antibodies using Avidin biotin ELISA. A two-stage random sampling methodology was followed for the collection of samples. Results from the present study revealed that the overall seropositivity was reported around $29.50 \%$ while the highest and lowest seropositivity of $43.39 \%$ and $16.66 \%$ were reported in the states of Sikkim and Assam respectively, followed by Mizoram (42.16\%), Manipur (29.86\%) and Meghalaya (27.40\%). Cattle of higher age groups showed the highest seropositivity compared to younger ones. A higher percent of IBR antibodies in cattle of NE states is a cause of concern and a detailed study on IBR prevalence comprising of a large number of the bovine population need to be undertaken.
\end{abstract}

* Corresponding author

E-mail: sharanspin13@gmail.com (Sharanagouda S. Patil)

Peer review under responsibility of Journal of Experimental Biology and Agricultural Sciences.

Production and Hosting by Horizon Publisher India [HPI] (http://www.horizonpublisherindia.in/).

All rights reserved.
All the articles published by Journal of Experimental Biology and Agricultural Sciences are licensed under a Creative Commons Attribution-NonCommercial 4.0 International License Based on a work at www.jebas.org.

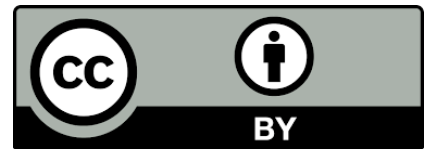




\section{Introduction}

Infectious bovine rhinotracheitis (IBR) is a highly contagious infectious disease caused by bovine herpesvirus type 1 (BoHV1) belonging to the genus Varicellovirus, subfamily Alphaherpesvirinae family Herpesviridae (Mc Lachlan \& Dubovi, 2011; Farooq et al., 2019). In India, the endemic IBR has caused a huge economic loss in the dairy industry due to a drop in milk production, repeat breeding, and abortions. The disease is characterized by respiratory symptoms (rhinotracheitis), abortions during the second and third trimester of pregnancy, repeat breeding, conjunctivitis, infectious pustular vulvovaginitis (IPV), and infectious balanoposthitis (IBP) (Raaperi et al., 2012). The virus gets transmitted by contact with infected animals, aerosol route, and virus-contaminated semen from BoHV-1 infected bulls. BoHV-1 infection often leads to latency, and such animals can act as a source of infection. Stress conditions, corticosteroid treatment, and transportation can activate the virus in latently infected animals, resulting inre-excretion of the virus (Jones et al., 2000).

Presently, four subtypes of bovine herpesvirus are known i.e. 1.1 and 1.2a (associated with infectious bovine rhinotracheitis), 1.2b (associated with infectious pustular vulvovaginitis and infectious balanoposthitis (IBP) and 1.3 (encephalitis) (Patil et al., 2012; Biswas et al., 2013). More often these serotypes cannot be differentiated by common serological tests and hence the studies describe them as IBR infected ones. Latent and subclinical infections are common in IBR (Ranganatha et al., 2013; Patil et al., 2017) which can be identified through the detection of antibodies against BoHV-1 in serum (Lemaire et al., 2000). Bovine herpesvirus-1 infection was first reported in India in 1976 (Mehrotra et al. 1976). Screening, surveillance, and monitoring are the three most important aspects to be considered to maintain the herd health status and to decrease the economic losses caused by this disease (Raizman et al., 2011). Information regarding the seroprevalence of IBR in the north eastern region of India are in scanty and only three reports viz., Suresh et al. (1999) those who reported 13.64\% prevalence in Assam; Chettri et al. (2016) those who recorded $20.34 \%$ prevalence of IBR in different organized farms in Guwahati, Assam and Nandi et al. (2011) showed the highest seroprevalence of IBR in Yaks in Assam. Keeping this in mind current study was planned to screen the cattle serum samples from the states of the northeast region of India.

\section{Materials and Methods}

A two-stage random sampling methodology was followed wherein the number of random and representative villages and the number of animals in each village were selected using a survey toolbox (Sergeant, 2018). A total of 3125 cattle (Holstein Friesian crossbred) serum samples representing 35 districts from five states viz., Assam, Manipur, Meghalaya, Mizoram, and Sikkim (Table $1 \mathrm{a} \& \mathrm{~b}$ ) were collected (Figure 1). The states have a hilly terrain except for Assam and the cattle population is remotely distributed, hence the sampling number was limited.

Serum samples were screened using Avidin Biotin ELISA (ICARNIVEDI) as per the described protocol. Briefly, all the controls (positive, negative, and conjugate controls), test samples, and other reagents were used and dissolved in blocking buffer (1\% bovine gelatin and $0.05 \%$ Tween 20) and dispensed in 100 ul of volume. The 1:100 diluted controls and test samples were dispensed to BoHV-1 antigen-coated plates. Later on, plates were incubated on a shaker at $37^{\circ} \mathrm{C}$ for $1 \mathrm{hr}$. Afterwards, the plates were washed 3 times with washing buffer (1X PBS with $0.05 \%$ Tween 20). Then, biotinylated anti-bovine IgG (1: 10,000 diluted in blocking buffer) raised in goats was added to all wells and incubated on a shaker at $37^{\circ} \mathrm{C}$ for $1 \mathrm{hr}$. Again, wash the plate as described earlier. Then add HRPO conjugated Avidin $(1: 10,000)$ to all wells and incubated at $37^{\circ} \mathrm{C}$ for $20 \mathrm{~min}$ and followed by the washing of the plate as described prior.

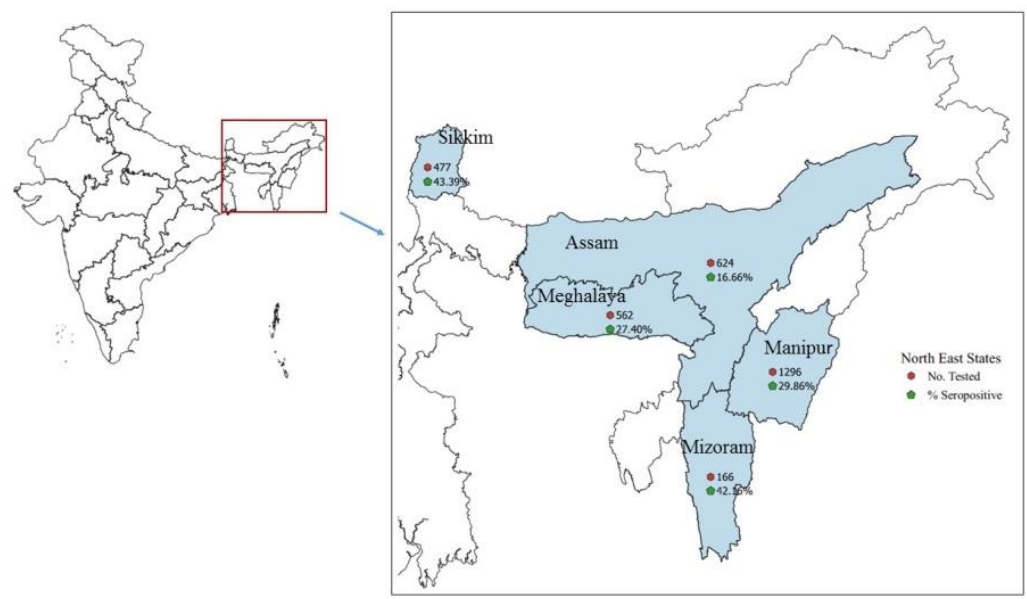

Figure 1 Location of bovine serum samples collected in five states of NE region of India

Journal of Experimental Biology and Agricultural Sciences

http://www.jebas.org 
Table 1a Details of cattle serum samples used in the study

\begin{tabular}{|c|c|c|c|c|c|c|c|c|c|c|c|c|c|c|}
\hline \multirow[b]{2}{*}{ S. N. } & \multirow[b]{2}{*}{ State } & \multicolumn{3}{|c|}{ 2014-15 } & \multicolumn{3}{|c|}{ 2015-16 } & \multicolumn{3}{|c|}{ 2016-17 } & \multicolumn{4}{|c|}{ Grand Total } \\
\hline & & 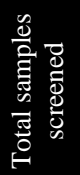 & 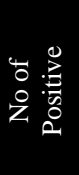 & 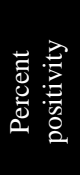 & 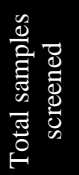 & 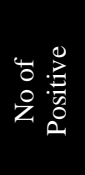 & 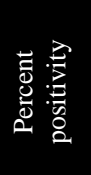 & 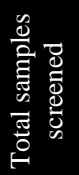 & 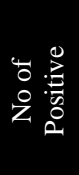 & 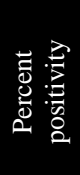 & 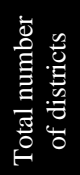 & 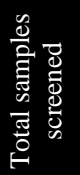 & 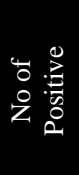 & 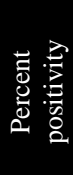 \\
\hline 1 & Assam & 80 & 5 & 6.25 & 228 & 17 & 7.46 & 316 & 82 & 25.95 & 11 & 624 & 104 & 16.66 \\
\hline 2 & Manipur & 169 & 67 & 39.64 & 412 & 102 & 24.76 & 715 & 218 & 30.49 & 9 & 1296 & 387 & 29.86 \\
\hline 3 & Meghalaya & 394 & 131 & 33.25 & 129 & 21 & 16.28 & 39 & 2 & 5.13 & 4 & 562 & 154 & 27.40 \\
\hline 4 & Mizoram & 31 & 10 & 32.26 & 55 & 23 & 41.81 & 80 & 37 & 46.25 & 7 & 166 & 70 & 42.16 \\
\hline 5 & Sikkim & 60 & 8 & 13.33 & 79 & 14 & 17.72 & 338 & 177 & 52.37 & 4 & 477 & 207 & 43.39 \\
\hline & Total & 734 & 221 & 30.10 & 903 & 177 & 19.60 & 1488 & 516 & 34.67 & 35 & 3125 & 922 & 29.50 \\
\hline
\end{tabular}

Table 1b State-wise seropositivity of IBR in north eastern states of India

\begin{tabular}{|ccccccc|}
\hline S1 No & State & $\begin{array}{c}\text { Total number of } \\
\text { districts }\end{array}$ & $\begin{array}{c}\text { Total samples } \\
\text { screened }\end{array}$ & No of Positive & $\begin{array}{c}\text { Percent } \\
\text { positivity }\end{array}$ & $\begin{array}{c}\text { True seropositivity at } \\
95 \% \text { CI }\end{array}$ \\
\hline 1 & Assam & 11 & 624 & 104 & 16.66 & $13.41(10.29-17.00)$ \\
\hline 2 & Manipur & 9 & 1296 & 387 & 29.86 & $28.58(25.78-31.50)$ \\
\hline 3 & Meghalaya & 4 & 562 & 154 & 27.40 & $25.75(21.70-30.15)$ \\
\hline 4 & Mizoram & 7 & 166 & 70 & 42.16 & $42.72(34.39-51.47)$ \\
\hline 5 & Sikkim & 4 & 477 & 207 & 43.39 & $44.13(39.10-49.29)$ \\
\hline & Total & 35 & 3125 & 922 & 29.50 & $28.17(26.36-30.03)$ \\
\hline
\end{tabular}

Later on, $100 \mathrm{ul}$ of TMB was added to all wells, incubate at $37^{\circ} \mathrm{C}$ for $6-8$ min, keep observing for colour development. This was followed by the addition of $50 \mathrm{ul}$ of $1 \mathrm{M}$ stop solution $\left(\mathrm{H}_{2} \mathrm{SO}_{4}\right)$ to all wells, and OD was measured at $450 \mathrm{~nm}$ (reference at $620 \mathrm{~nm}$ ) (Annual Report, 2018). The sensitivity and specificity of the assay were found to be $92 \%$ and $95 \%$ respectively. There was no crossreactivity between the samples as the antigen was precipitated and purified with polyethylene glycol (PEG). Results were interpreted as below,

\section{' $\mathrm{X}$ '= Average OD of Strong Positive x 0.64}

The test sample is positive if its OD values are greater than ' $\mathrm{X}$ '; the Test sample is negative if its OD values are less than ' $\mathrm{X}$ '

Appropriate and applicable statistical analysis such as chi-square test and confidence interval were calculated.

\section{Results and Discussion}

A total of 3125 cattle serum samples representing 35 districts from five states viz., Assam, Manipur, Mizoram, Meghalaya, and Sikkim were collected. Except for Assam, all the other states have hilly terrain, and cattle were housed remotely in different parts of the location. Cumulative seropositivity of $29.50 \%$ (922/3125) [28.17 (95\%CI: 26.36-30.03)] was found to be on the higher side and was significant $(\chi 2=108, p=0.001)$.
Assam showed IBR seropositivity of $16.66 \%$ (Table 2). In Assam, earlier studies have reported seroprevalence of $13.64 \%$ in cattle (Suresh et al., 1999), $71.10 \%$ in Yak (Nandi et al., 2011), and $20.34 \%$ in cattle (Chettri et al., 2016). When the seroprevalence was compared between different ages of cattle, it was found that the cattle of 4 years of age showed the highest seropositivity of $21.46 \%$ followed by $14.47 \%$ in cattle of 3 years of age and $12.89 \%$ in cattle of 5 years of age. Although the cattle of 4 years of age in their peak of productivity showed the highest seropositivity, with not that significant values of $\chi 2=6.92, p=0.031$. Assam is the focal point for all dairy farming-related activities to cater to the needs of other states of north eastern states. Moreover, Assam shares a border with Bhutan which is very porous wherein there is no ban on the movement of man and animals.

Seropositivity of $29.86 \%$ was recorded in Manipur (Table 3). Cattle of 5 years of age showed seropositivity of $39.79 \%$, followed by $24.20 \%$ seropositivity in cattle of 3 years of age, and cattle of 4 years of age revealed seropositivity of $20.65 \%$. The highest seropositivity was recorded in cattle of 5 years of age which may be attributed to their peak productivity. Seropositivity amongst different age groups of cattle was insignificance with $\chi 2=50.80$ and $p=0.001$. Suresh et al. (1999) showed a seroprevalence of $51.11 \%$ in Manipur which was found to be very high. Manipur also shares a border with other states Myanmar wherein the influx of materials into the state is very high. 
Table 2 Age wise seropositivity of IBR in Assam

\begin{tabular}{|c|ccccc|}
\hline \multirow{4}{*}{ Assam } & Age in Years & Total tested & Total positive & Percent positivity & True seropositivity at 95\% CI \\
\cline { 2 - 6 } & 3 & 152 & 22 & 14.47 & $10.89(5.47-18.32)$ \\
\cline { 2 - 6 } & 4 & 247 & 53 & 21.46 & $18.92(13.56-25.28)$ \\
\cline { 2 - 6 } & 5 & 225 & 104 & 12.89 & $16.07(4.74-14.82)$ \\
\hline \multicolumn{7}{|c}{$\chi^{2}=6.92$} & $p=0.031$ & $13.41(10.29-17.00)$ \\
\hline
\end{tabular}

Table 3 Age wise seropositivity of IBR in Manipur

\begin{tabular}{|c|ccccc|}
\hline \multirow{4}{*}{ Manipur } & Age in Years & Total tested & Total positive & Percent positivity & True seropositivity at 95\% CI \\
\cline { 2 - 6 } & 3 & 219 & 53 & 24.20 & $22.07(16.10-29.07)$ \\
\cline { 2 - 6 } & 4 & 494 & 102 & 20.65 & $17.99(14.15-22.34)$ \\
\cline { 2 - 6 } & 5 & 583 & 232 & 39.79 & $28.99(35.52-44.62)$ \\
\hline \multicolumn{7}{|c}{$\chi 2=50.80$} & $p=0.001$ & 29.86 & $25.78-31.50)$ \\
\hline
\end{tabular}

In Meghalaya seropositivity was recorded at $27.40 \%$ (Table 4). However, seropositivity of $19.56 \%$ was reported during 2001-2009 (ICAR, 2010: http://www.kiran.nic.in/sero-prevalence.html) which might be attributed to easy movement of men and material as along with animals since they do not have demarcated boundaries. Cattle of 4 years of age showed seropositivity of $34.08 \%$, followed by $30.56 \%$ seropositivity in cattle of 5 years of age and $19.19 \%$ seropositivity in cattle of 3 years of age with not so significant values of $\chi 2=8.06$ and $p=0.018$. There were not many reports on IBR seroprevalence from Meghalaya state.

A significant difference was seen in the seropositivity of IBR among the different age groups of cattle $\left(\chi^{2}=27.0, p=0.001\right)$ of Mizoram. Suresh et al. (1999) showed a seroprevalence of $13.64 \%$ in Mizoram which was less compared to that shown in the present study $(42.17 \%$ ) (Table 5). Cattle of 5 years of age showed $75 \%$ seropositivity, which was in the peak productivity period and $27.27 \%$ seropositivity was recorded in cattle of 3 years of age. Mizoram shares a border with Myanmar and Bangladesh wherein there is no restriction on the movement of animals.

Sikkim is a small state that depends on Assam and West Bengal for its dairy needs. From this state, $43.39 \%$ seropositivity was recorded (Table 6). The highest seropositivity was observed among the 5 years age group cattle's while the lowest seropositivity was recorded in 3 years of age cattle's which was found to be highly significant $(\chi 2=27.2, p=0.001)$. In general, it was reported that the animals of a higher age group of 9 years showed the highest seropositivity of $45.9 \%$ when compared with the younger ones of 2 years of age $(6.89 \%)$ (Samrath et al., 2016).

Table 4 Age wise seropositivity of IBR in Meghalaya

\begin{tabular}{|c|ccccc|}
\hline \multirow{3}{*}{ Meghalaya } & Age in Years & Total tested & Total positive & Percent positivity & True seropositivity at 95\% CI \\
\cline { 2 - 6 } & 3 & 99 & 19 & 19.19 & $16.31(8.79-26.48)$ \\
\cline { 2 - 6 } & 4 & 355 & 121 & 34.08 & $33.43(27.99-39.27)$ \\
\cline { 2 - 6 } & 5 & 108 & 33 & 30.56 & $29.37(20.30-39.98)$ \\
\hline \multicolumn{7}{|c}{$\chi^{*} 2=8.06$} & $p=0.018$ & 27.40 & $25.75(21.70-30.15)$ \\
\hline
\end{tabular}

Table 5 Age wise seropositivity of IBR in Mizoram

\begin{tabular}{|c|ccccc|}
\hline & Age in Years & Total tested & Total positive & Percent positivity & True seropositivity at 95\% CI \\
\hline \multirow{4}{*}{ Mizoram } & 3 & 66 & 18 & 27.27 & $25.60(14.95-39.13)$ \\
\cline { 2 - 6 } & 4 & 56 & 19 & 33.93 & $33.25(20.60-48.28)$ \\
\cline { 2 - 6 } & 5 & 44 & 33 & 75.00 & $80.46(63.86-92.44)$ \\
\cline { 2 - 6 } & \multicolumn{7}{c}{$\chi 2=27.0$} & $p=0.001$ & 42.17 & $42.72(34.39-51.47)$ \\
\hline
\end{tabular}

Table 6 Age wise seropositivity of IBR in Sikkim

\begin{tabular}{|c|c|c|c|c|c|}
\hline & Age in Years & Total tested & Total positive & Percent positivity & True seropositivity at $95 \% \mathrm{CI}$ \\
\hline \multirow{5}{*}{ Sikkim } & 3 & 87 & 27 & 31.03 & $29.92(19.87-41.82)$ \\
\hline & 4 & 169 & 56 & 33.14 & $32.34(24.69-40.85)$ \\
\hline & 5 & 221 & 124 & 56.11 & $58.75(51.17-66.08)$ \\
\hline & & 477 & 207 & 43.40 & $44.13(39.10-49.29)$ \\
\hline & & & $\chi 2=27.2$ & $p=0.001$ & \\
\hline
\end{tabular}




\section{Conclusion}

IBR is endemic in India especially in the five states of north eastern states of the country. Seroprevalence of IBR showed the presence of IBR antibodies in animals with the indication of the presence of disease in the herd. Very few reports on the seroprevalence of IBR in the NE region are available; hence efforts were made to detect IBR antibodies in the cattle population in the NE region of India. Sikkim showed the highest seroprevalence while Assam revealed the lowest seropositivity of IBR. NE region is strategically located and has porous international borders with Myanmar, Bangladesh, and Bhutan wherein there is no restriction of movement of animals. Therefore, there should be strict vigilance on the movement of animals especially considering the health status of animals alongside international borders.

\section{Acknowledgments}

The authors are grateful to DBT, New Delhi for funding this study which was conducted under the twinning programme with north eastern states of India. Thanks are also due to DG, DDG (AS), ICAR, and the Director of the Institute for their constant support and guidance during the study period.

\section{Conflict of Interest}

The authors declare that there is no conflict of interest

\section{Financial Statement}

The study was funded by DBT, New Delhi (No: BT/393/NE/TBP/2012)

\section{References}

Annual Report (2018) ICAR-National Institute of Veterinary Epidemiology and Disease Informatics (NIVEDI), Bengaluru, Pp. 16.

Biswas S, Bandyopadyay S, Dimri U, Patra PH (2013) Bovine herpesvirus-1 (BHV-1) - a re-emerging concern in livestock: a revisit to its biology, epidemiology, diagnosis, and prophylaxis. Veterinary Quarterly 33: 68-81.

Chettri S, Ahmed K, Bora DP, Dutta LJ, Bora M, Sharma DK (2016) Reproductive Status in Bovine Herpes Virus 1 (BHV-1) sero-positive Dairy Cattle. Indian Journal of Animal Reproduction 36(2):53-56.

ICAR (2010) Salient achievements pertaining to disease diagnosis during the period under ADMAS. Available at http://www.kiran.nic.in/sero-prevalence.html access on 18th November 2020.
Farooq S, KumarA, Chaudhary S,Maan S (2019) Bovine Herpesvirus 1 (BoHV-1) in Cattle and Buffalo: A Review with Emphasis on Seroprevalence in India. International Journal of Current Microbiology and Applied Sciences 8(12): 28-35.

Jones C, Newby TJ, Holt T, Doster A, Stone M, Ciacci-Zanella J, Webster CJ, Jackwood MW (2000) Analysis of latency in cattle after inoculation with a temperature sensitive mutant of bovine herpesvirus 1 (RLB106). Vaccine 18(27):3185-3195.

Lemaire M, Meyer G, Baranowski E, Schynts F, Wellemans G, Kerkhofs P, Thiry E (2000) Production of Bovine Herpesvirus Type 1-Seronegative Latent Carriers by Administration of a LiveAttenuated Vaccine in Passively Immunized Calves. Journal of Clinical Microbiology 38(11):4233-4238.

Mac Lachlan NJ, Dubovi EJ (2011) In Fenner's Veterinary Virology. 4th ed. Academic Press, London.

Mehrotra ML, Rajya BS, Kumar S (1976) Infectious bovine rhinotracheitis (IBR) kerato-conjuctivitis in calves. Indian Journal of Veterinary Pathology 1: 70-73.

Nandi S, Kumar M, Yadav V, Chander V (2011) Serological evidences of bovine herpesvirus-1 infection in bovines of organized farms in India. Transboundary Emerging Disease 58: 105-109.

Patil SS, Hemadri D, Veeresh H, Chandranaik BM, Prabhudas K (2012) Genetic characterization of BoHV-1 isolates in India. Indian Journal Animal Science 82: 848-850.

Patil SS, Prajapati A, Krishnamoorthy P, Desai GS, Reddy GBM, Suresh KP, Rahman H (2017) Seroprevalence of infectious bovine rhinotracheitis in organized dairy farms of India. Indian Journal Animal Research 51 (1): 151-154.

Raaperi K, Bougeard S, Aleksejev A, Orro T, Viltrop A (2012) Association of herd BHV-1 seroprevalence with respiratory disease in young stock in Estonian dairy cattle. Research in Veterinary Science 93: 641-648.

Raizman EA, Pogranichniy R, Negron M, Schnur M, Tobar-Lopez DE (2011) Seroprevalence of infectious bovine rhinotracheitis and bovine viral diarrhea virus type 1 and type 2 in non-vaccinated cattle herds in the Pacific Region of Central Costa Rica. Tropical Animal Health and Production 43: 773-778.

Ranganatha S, Rathnamma D, Patil SS, Chandranaik BM, Isloor S, Veeregowda BM, Narayanabhat M, Srikala (2013) Isolation and molecular characterization of bovine herpes virus-1 by polymerase chain reaction. Indian Journal of Animal Research 47: 340-343. 
Samrath D, Shakya S, Rawat N, Gilhare VR, Singh F, Khan FF (2016) Seroprevalence of bovine herpes virus type 1 in cattle and buffaloes from Chhattisgarh. Journal of Animal Research 6(4): 641-644.

Sergeant ESG (2018) Epitools Epidemiological Calculators.
Ausvet. Available at: http://epitools.ausvet.com.au access on $19^{\text {th }}$ October 2020.

Suresh KB, Sudarshan K, Rajasekhar M (1999) Seroprevalence of infectious bovine rhinotracheitis in India. Indian Veterinary Journal 76 (1): 5-9. 